\title{
O queer em rede: subversão e (des)construção do gênero na página do Facebook Travesti Reflexiva
}

\author{
Hedilberto Pessoa Berto Júnior ${ }^{1}$
}

Resumo: O artigo tem como objetivo analisar as publicações (textos, vídeos, imagens e comentários) da página do Facebook Travesti Reflexiva, comunidade voltada para discussões que subvertem as imposições heteronormativas, na qual são abordadas temáticas que vão desde a identidade do indivíduo trans* até os direitos básicos das minorias socialmente oprimidas. Para isso, a pesquisa utiliza em sua base teórica não somente autores da Teoria Queer ${ }^{2}$, como também aqueles que estudam as mudanças sociais advindas com as ferramentas de comunicação no ciberespaço, partindo do pressuposto que, a partir desses novos processos de comunicabilidade, as pessoas comuns - que não pertencem à grande mídia - têm autonomia para propagar ideias e ideais subversivos.

Palavras-chave: Redes sociais; Teoria Queer; subversão; transexualidade.

\begin{abstract}
This paper aims to analyse the publications (texts, videos, images and coments) from the Facebook page "Travesti Reflexiva", a community oriented to discussions that subvert the heteronormative impositions by approaching themes that go from the identity of the trans* individual until the basic rights of minorities socially opressed. To do this, the research uses in its theoretical bases not only authors from the queer theory but also those who study the social transformations emerged along with the comunication tools on the cyberspace, assuming that from these new comunication processes, common people - who don't belong to the grande media - are free to disseminate subversive ideas and ideals.
\end{abstract}

Keywords: Social Networks; Queer Theory; subversion; transsexuality.

Resumén: El artículo tiene como objetivo analizar las publicaciones (textos, vídeos, fotos y comentarios) del Facebook "Travestí Reflexiva", debates orientados a la comunidad que subvierten las imposiciones página heteronormatividad, que son temas tratados van desde la identidad de la persona trans * incluso los derechos básicos de las minorías socialmente oprimidos. Para eso, la investigación utiliza en su base teórica autores no sólo de la teoría queer, así como aquellos que estudian los cambios sociales que se derivan de las herramientas de comunicación en el ciberespacio, en el supuesto de que, a partir de estos nuevos procesos de comunicabilidad, la gente común - fuera de la corriente principal de los medios de comunicación - están facultados para difundir las ideas y los ideales subversivos.

Palabras clave: Redes Sociales; Teoría Queer; subversión; transexualidad.

\section{Introdução}

Apesar dos Parâmetros Curriculares Nacionais (PCNs) colocarem como tema transversal de discussão na educação básica brasileira questões relativas à sexualidade, ainda é difícil encontrar a temática difundida com solidez e completude nas instituições de ensino do país, conforme mostra Andrea Martelli e Camila Aquino, em Escola e educação sexual: uma relação necessária (2012), no qual é observado que o assunto ainda é limitado a uma visão biologizante dentro das escolas, deixando de lado os condicionantes econômicos, culturais, sociais, políticos e históricos.

1 Mestrando do Programa de Pós-graduação em Comunicação e Culturas Midiáticas Audiovisuais (PPGC) da Universidade Federal da Paraíba (UFPB).

2 Quando se referir à teoria, o "Queer”, como substantivo, aparece em letra maiúscula; quando se referir ao queer como adjetivo, ficará em minúscula. 
Ao contrário do que vem acontecendo na grade curricular das escolas do país, que deveria ser a base para construção de realidades sociais, nas redes sociais as questões de gênero estão cada vez mais afloradas, com posicionamentos sólidos tanto daqueles que defendem uma causa social como também dos que lutam contra ela, fazendo com que esses espaços virtuais se tornem ambientes ricos para iluminar o pensamento acerca das identidades de gênero. Um desses exemplos é a página Travesti Reflexiva, que, apesar de ter sido criada em fevereiro de 2014, em julho do mesmo ano já possuía mais de 65 mil seguidores (curtidas).

Criada pela sergipana Sofia Favero, a página é um dos mais importantes espaços tanto para militância que defende o direito de reconhecimento à pessoa trans ${ }^{* 3}$ (aqui entendida como todos os indivíduos transgêneros, ou seja, que não reconhecem a sua identidade de gênero conforme aquela que lhe foi dada no nascimento, em detrimento de seu sexo biológico), como para todos que vivem o preconceito de ser "minoria"4 social (homossexuais, bissexuais, assexuados, drag queens, negros, mulheres cisgêneras ${ }^{5}$, entre outros) e também para quem simplesmente deseja entender um pouco mais acerca do universo das identidades de gênero.

Utilizando materiais midiáticos dos mais variados possíveis, como ilustrações, fotografias, vídeos e textos, a página consegue em poucos minutos levantar dezenas de compartilhamentos, centenas de curtidas e, o mais importante, inúmeras discussões e reflexões sobre as possibilidades identitárias dos indivíduos.

A pesquisa aqui proposta analisou as postagens realizadas entre os meses de junho e julho de 2014, não somente para fins metodológicos e organizacionais, como também por serem meses de forte movimentação nas redes sociais, em detrimento da Copa do Mundo, que criou uma movimentação atípica na internet, com grupos que defendiam e outros que combatiam o evento.

Antes de adentrar na análise da página e discutirmos o porquê do espaço ser considerado um importante exemplo de como as redes sociais podem ajudar na construção de novas realidades, e, mais precisamente, como podem deixar aflorar pensamentos queer, através da discussão e reflexão acerca das questões de gênero, é necessário entender como as relações sociais estão mudando com a popularização dessas novas tecnologias da informação, como Twitter, Instagram e, no caso do estudo aqui proposto, o Facebook, fazendo com que as pessoas ganhem mais um canal para difusão e absorção de conhecimentos.

3 O asterisco é usado para representar a ideia de guarda-chuva que engloba todos os indivíduos transgêneros, ou seja, pessoas que ultrapassaram em algum momento da vida a fronteira identitátia que lhe foi dada ao nascer.

4 Aqui "minorias" são pessoas que fogem da lógica de inteligibilidade social imposta pela norma dominante, que privilegia pessoas brancas, letradas, heterossexuais e de classe média/alta. Assim, a minoria não está ligada necessariamente a escassez dessas pessoas na sociedade, mas, antes de tudo, a forma como são tratadas pela lógica dominante, que cessa seus direitos e tentam transformá-los em uma parcela inaudível da população.

5 Em sua definição, o indivíduo cisgênero é oposto ao transgênero, uma vez que sua identidade de gênero (afirmar e se reconhecer enquanto mulher ou homem) condiz com sua genitália, logo com o gênero que é imposto através do sexo biológico. Ou seja, os nascidos com pênis se reconhecem enquanto homens e as nascidas com vagina se enxergam como mulher. 


\section{Redes sociais: novas experiências de informação a poucos cliques}

Não importa o tamanho da tela. Seja no desktop, notebook, tablet, smartphone ou até mesmo nas Smart TVs, as redes sociais estão mais presentes na vida dos indivíduos e se tornaram ferramentas para propagar ideias, denunciar problemas, reivindicar direitos ou simplesmente relatar fatos cotidianos de relevância para uma pessoa ou grupos específicos.

Segundo dados da Pesquisa Nacional por Amostra de Domicílios (PNAD), divulgada em 18 de setembro de $2014^{6}$ pelo Instituto Brasileiro de Geografia e Estatística (IBGE), quase metade da população brasileira (49,4\%) possuía acesso à internet em 2013, passando de 84,2 milhões de usuários, em 2012, para 85,5 milhões de internautas no ano de referência, acréscimo de 1,3 milhão de pessoas.

Independente de seu uso, seja para entretenimento, ativismo, estudo ou qualquer outra possibilidade, os números mostram a inegável mudança nos hábitos cotidianos alcançados pelo advento das novas tecnologias da comunicação, conforme assinala Cláudio Paiva em Hermes no ciberespaço: uma interpretação da comunicação e cultura na era digital (2013):

No plano das estruturas do cotidiano há novos modos de interação e sociabilidade mediados pela tecnologia, que animam os diálogos e as conversações dos indivíduos e grupos, criando um estilo de conjunção e magnetismo reorganizados das experiências coletivas através das redes sociais. (PAIVA, 2013, p.58)

$\mathrm{Na}$ sua obra, o autor deixa claro que as novas ferramentas de comunicação trouxeram novas possibilidades para a propagação dos discursos, afetando a forma como a sociedade se expressa nos mais variados segmentos. A pesquisadora Raquel Recuero também enfatiza os novos processos de sociabilidade trazidos com as tecnologias da comunicação. Em Redes Sociais na internet (2009), a autora reforça a ideia de transformação que vem acontecendo nas relações sociais dos indivíduos.

Esses fenômenos representam aquilo que está mudando profundamente nas formas de organização, identidade, conversação e mobilização social: o advento da Comunicação Mediada pelo Computador. Essa comunicação, mais do que permitir aos indivíduos comunicar-se, amplificou a capacidade de conexão, permitindo que redes fossem criadas e expressas nesses espaços: as redes sociais mediadas pelo computador (RECUERO, 2009, p. 16).

A rede de sociabilidades, ou seja, essa teia que interliga várias mentes em um espaço, deixou de ser somente física e passou a ocorrer, sobretudo, no mundo virtual, no qual diversos atores sociais se tocam e se influenciam em variados processos comunicacionais, independente de sua localização geográfica. Essas mudanças sociais acontecem em níveis amplos, sendo a independência da pessoa comum a mais significativa.

Com a popularização da tecnologia e das redes sociais, os indivíduos não precisam mais da mídia tradicional (televisão, jornal, revista, etc.) para levantar questionamentos e brigar por suas

6 Apesar de divulgada nesta data, a pesquisa da Tabela 8.3, relativa ao percentual de pessoas com acesso à internet, passou por uma correção e foi reapresentada no dia 19 de setembro de 2014. Os dados aqui apresentados são da pesquisa já corrigida. Disponível em http://bit.ly/1vnsLbu 
causas. Graças às novas experiências coletivas, é possível levantar discussões a nível global sem intervenção daqueles que antes dominavam a pauta cotidiana.

Essa autonomia do sujeito comum é bastante debatida em $O$ show do eu: a intimidade como espetáculo (2008), onde Paula Sibilia reforça as várias possibilidades dos usuários dentro desse novo universo virtual, enfatizando que graças aos novos processos e usos das mídias digitais a sociedade vem passando por transformações significativas.

Acontece que você e eu, todos nós, estamos "transformando a era da informação". Estamos modificando as artes, a política e o comércio, e até mesmo a maneira de percebermos o mundo. (...) Em virtude desse estouro de criatividade (e de presença midiática) entre aqueles que costumavam ser meros leitores e espectadores passivos, teria chegado a "hora dos amadores". (SIBILIA, 2008, p. 8 e 9)

E os amadores se mostram fortemente presentes nessas redes sociais. Somente no Brasil, o Facebook contabilizava 61,2 milhões de usuários ativos quando comemorava seu $10^{\circ}$ aniversário, no dia 04 de fevereiro de 2014, segundo dados fornecidos pela empresa e apresentados pelo Uol Tecnologia ${ }^{7}$. Neste cenário, a Travesti Reflexiva se comporta como mais um espaço de discussão e propagação de ideias dos amadores, pessoas comuns que habitam aquele universo virtual para gerar reflexões acerca de suas realidades.

Para entender as movimentações dentro desse crescente ambiente, e mais precisamente, como são levantadas determinadas discussões na página, é preciso analisar desde sua estrutura organizacional até as interações que ocorrem naquele espaço, para daí compreender como ela representa uma importante ferramenta para uma reflexão queer acerca das identidades de gênero.

\section{Travesti Reflexiva: espírito queer no mundo virtual}

Com mais de 65 mil curtidas (em julho de 2014), a página Travesti Reflexiva é um espaço de constante movimentação, graças tanto as postagens diárias da proprietária da página, Sofia Favero, como também pelos diversos comentários e, consequentemente, discussões realizadas naquele ambiente.

Partindo do pensamento de Raquel Recuero (2009, p.32) acerca dessas movimentações, a página analisada possui interação mútua, pois, ao contrário do que acontece nas interações reativas, aqui os relacionamentos são mantidos em constância entre a proprietária da página e seus seguidores. Uma postagem gera diversos comentários, que por sua vez geram outros comentários acerca do que foi dito naquela postagem, criando um extenso espaço de discussão entre os indivíduos.

É preciso observar que essa forte movimentação é resultado de fatores subjetivos e objetivos próprios das formas de diálogo que chegaram junto com as novas tecnologias da comunicação. Paula Sibilia (2008) diz que alguns elementos contribuem para que as redes sociais tenham efetivação de usuários. No aspecto subjetivo, a empatia é o principal elemento que vai efetivar a constante participação de um usuário em determinada página da rede social.

7 Disponível em http://bit.ly/11JI3DF. Acessado em 14/07/2014. 
No caso da Travesti Reflexiva, a propriedade do discurso é uma das razões para que essa identificação entre usuários e proprietário da página aconteça: Sofia Favero, que é mulher trans, fala sobre questões de identidade de gênero para outras pessoas que também se interessam por aquele assunto, seja porque vivem em uma realidade identitária parecida ou porque desejam entender melhor sobre aquele universo. Logo, nada melhor do que alguém dentro desta realidade para falar aos demais. Sobre esse discurso de propriedade e os processos de identificação e empatia que ocorre entre usuários nas redes sociais, Paula Sibilia (2008) diz que

Talvez isso aconteça porque esses relatos estão envolvidos em um halo autoral que remete, por definição, a uma certa autenticidade - algo que se hospeda no próprio coração do "pacto de leitura" antes mencionado - e implica uma referência a alguma verdade, um vínculo com uma vida real e com um eu que assina, narra e vive o que se conta (SIBILIA, 2008, p. 37)

Assim como anos atrás o discurso jornalístico, sempre vendido como um relato do real, foi legitimado por boa parte dos consumidores de informação, que criaram (e ainda criam) pactos fiduciários com suas fontes, usando-as como remetente seguro de informação, agora esse mesmo contrato é percebido com os autores de discursos nas redes sociais.

Ainda sobre a aproximação e confiança que tem o usuário da internet para com aqueles que seguem nos mundos virtuais, Paula Sibilia (2008) destaca aquilo que chama de "polo objetivo" das novas experiências midiáticas. No seu dizer, são os textos, sons e imagens colocados nas páginas, elementos que servem de atração para que os usuários continuem naquele espaço, uma vez que a forma narrada foge ao tédio e aos limites que muitos "discursos de propriedade" impõem.

É habitual o recurso da transcrição literal da fonética e um tom coloquial que evoca as conversas cotidianas. (...) Sua feitura não se apoia em parâmetros tipicamente literários ou letrados, nem de maneira explícita, nem tampouco implícita nas entrelinhas ou no sentido do gesto escritural (SIBILIA, 2008, p. 37 e 38)

Percebe-se na análise que a narrativa da página Travesti Reflexiva não está preocupada com as normas cultas da escrita. Antes de escrever correto (a forma "certa" da gramática) há a preocupação em dizer o incorreto, subverter a lógica normativa ao abrir e fundamentar o discurso baseado nas múltiplas possibilidades de identidades de gênero. O intuito é propagar a ideia daqueles que não se enquadram nos modelos binários pregados como legítimos dentro da sociedade, que devem contrariar certas lógicas pré-estabelecidas. Um exemplo disso pode ser visto na publicação do dia 21 de julho de 2014 (Fig. 1). 
Fig. 1: Discursos subversivos contra a lógica imposta de gênero

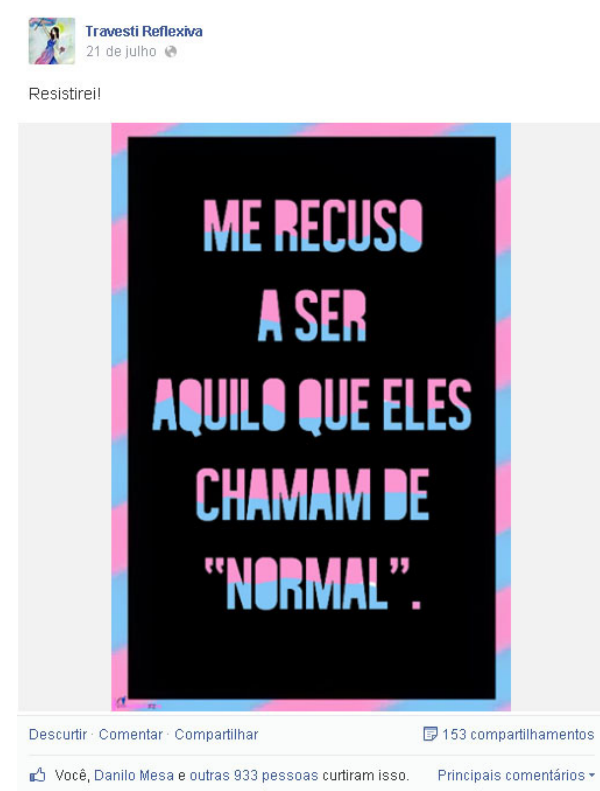

Fonte: página Travesti Reflexiva ${ }^{8}$

Na postagem, a imagem revela muito da proposta daquela página. Escrita nas cores da bandeira que representa o orgulho transgênero, a frase "Me recuso a ser aquilo que eles chamam de "normal" é o exemplo queer do subversivo, dos inconformados e não pertencentes àquelas ideias socialmente impostas como corretas. Na legenda da imagem, a exclamativa "Resistirei!" reforça a ideia de quem quer ruir as lógicas binárias das identidades de gênero.

Ao negar um pertencimento àquilo defendido pela sociedade como "normal", esvaecendo a solidez das normas as quais os indivíduos são impostos na sociedade, é levantada uma das principais bandeiras queer: a não aceitação das regras colocadas como verdades concretas, questionando aquilo encarado como realidade "certa" a ser seguida.

Conforme explica Guacira Lopes, em Um corpo estranho: ensaios sobre sexualidade e Teoria Queer, o pensamento queer surge da não conformidade com regras pré-estabelecidas e previamente aprovadas. Uma das propostas desse movimento é combater a concretude das imposições e pensar em novas lógicas de afirmação das identidades, escapando das "diferenças" assimiláveis, binárias e higienistas. O queer "representa claramente a diferença que não quer ser assimilada ou tolerada, e, portanto, sua forma de ação é muito mais transgressiva e perturbadora” (p.39).

De acordo com a autora, a identidade de gênero é cristalizada desde muito cedo na vida social, forçando, na maioria das vezes, os indivíduos a carregar uma marca corporal imposta que perdura por toda sua trajetória de vida, obrigação esta pouco dialógica e condicionante, sempre construída por bases biológicas (a "natureza" cromossômica do sexo) e/ou religiosas (o "certo" e o "errado" segundo os preceitos bíblicos, por exemplo). 
A declaração "É uma menina!" ou "É um menino" também começa uma espécie de "viagem", ou melhor, instala um processo que, supostamente, deve seguir um determinado rumo ou direção. A afirmativa, mais do que uma descrição, pode ser compreendida como uma definição ou decisão sobre um corpo (...) a afirmação "é um menino" ou "é uma menina" inaugura um processo de masculinização ou de feminilização com o qual o sujeito se compromete. Para se qualificar como um sujeito legítimo, como um "corpo que importa" (...) o sujeito se verá obrigado a obedecer às normas que regulam sua cultura (LOURO, 2008, p. 15 e 16)

Nas postagens da página Travesti Reflexiva são recorrentes as discussões sobre a natureza e legitimidade do sexo, gênero e corpo. Isso já pode ser visto na análise dos aspectos que antecedem as publicações, ou seja, nas informações que aparecem antes dos textos e imagens carregados na timeline (linha do tempo) ${ }^{9}$. Na descrição da página, a autora principal da conta, no caso Sofia Favero, diz que naquele espaço contém "Desventuras de uma mente perturbada pela aplicação errada de hormônios injetáveis".

A não negação de um corpo "moldado" é um forte discurso acerca da forma feminina trans, porque quebra a ideia de naturalidade de um corpo, do gênero e da sexualidade, tão enraizado na sociedade como fundamentos essenciais para a legitimação de um indivíduo. Essa desconstrução, segundo Leandro Colling (2012), é um dos caminhos para se construir uma sociedade livre da heterossexualidade compulsória e da heteronormatividade ${ }^{10}$ que impera quando se pensa as identidades de gênero e as sexualidades que fogem ao modelo consagrado como o "correto".

Para combater a falta de respeito à diversidade sexual e de gênero existente é preciso evidenciar que não existe sexualidade normal, natural ou que seja um designo de Deus ou coisa do tipo. Os estudos queer apontam (...) que a própria heterossexualidade não é fruto apenas da natureza, mas é uma imposição sobre todas as pessoas, imposição essa que inicia, muitas vezes, antes de nosso próprio nascimento. (COLLING, 2012, p. 123)

Na observação do pesquisador, a imposição de uma naturalidade biológica ou religiosa acerca da sexualidade deve ser um dos principais questionamentos quando se debate as questões de gênero, porque ela obriga o sujeito a seguir um trajeto de vida que nem sempre condiz com aquilo que ele considera como legítimo do seu Eu.

A manifestação e propagação de um discurso que enfatize a não naturalidade do gênero, como se observa na página analisada, trinca a grossa camada do discurso biológico e religioso que há centenas de anos moldam e amarram as potencialidades da sexualidade, rompe com a ideia de conformação pelo "sexo abençoado": os consagrados com pênis devem viver como homens (macho, viril, heterossexual, dominante, livre, etc.) e os abençoados com vagina devem ser mulheres (feminina, delicada, heterossexual, dominada, subordinada, etc.).

Conforme observa Leandro Colling (2012), esse tipo de quebra dos paradigmas é essencial para se pensar nas múltiplas possibilidades e também desconsagrar aquilo considerado como verdade

9 Espaço onde são inseridas e dispostas em ordem cronológica as publicações da página.

10 Heteronormatividade é o modelo de vida heterossexual como norma. Pessoas educadas e moldadas pela sociedade para agir seguindo uma lógica do "correto". 
absoluta sobre a sexualidade, uma vez que nenhuma sexualidade é uma verdade da natureza, se assim o fosse não seria necessário o constante aparato de vigilância e regulação imposto na sociedade contemporânea.

\begin{abstract}
Senão vejamos: se a heterossexualidade fosse um dado exclusivo da natureza, por que seria tão necessário vigiar os corpos e comportamentos de nossas crianças para que todas sejam heterossexuais? (...) precisamos descontruir essa "verdade" sobre a sexualidade que, de tão arraigada em nossas mentes, já foi naturalizada pelas pessoas (COLLING, 2012, p.123)
\end{abstract}

Além da tentativa de quebrar essa natureza biológica do gênero, há outros elementos que mostram o que há de queer na página Travesti Reflexiva. A recusa e subversão também são vistas em outros elementos da página, sobretudo nas expressões imagéticas utilizadas. O avatar da página, por exemplo, é uma ilustração feminina que lembra a fisionomia da proprietária daquela conta, Sofia Favero. A imagem (Fig. 2) mostra a figura hasteando a bandeira do orgulho transexual, em posição semelhante à pintura A liberdade guiando o povo (La Liberté guidant le peuple, 1830), do pintor francês Eugène Delacroix.

Fig.2: - Mulheres revolucionárias: avatar da página (esq.) e Delacroix (dir.)
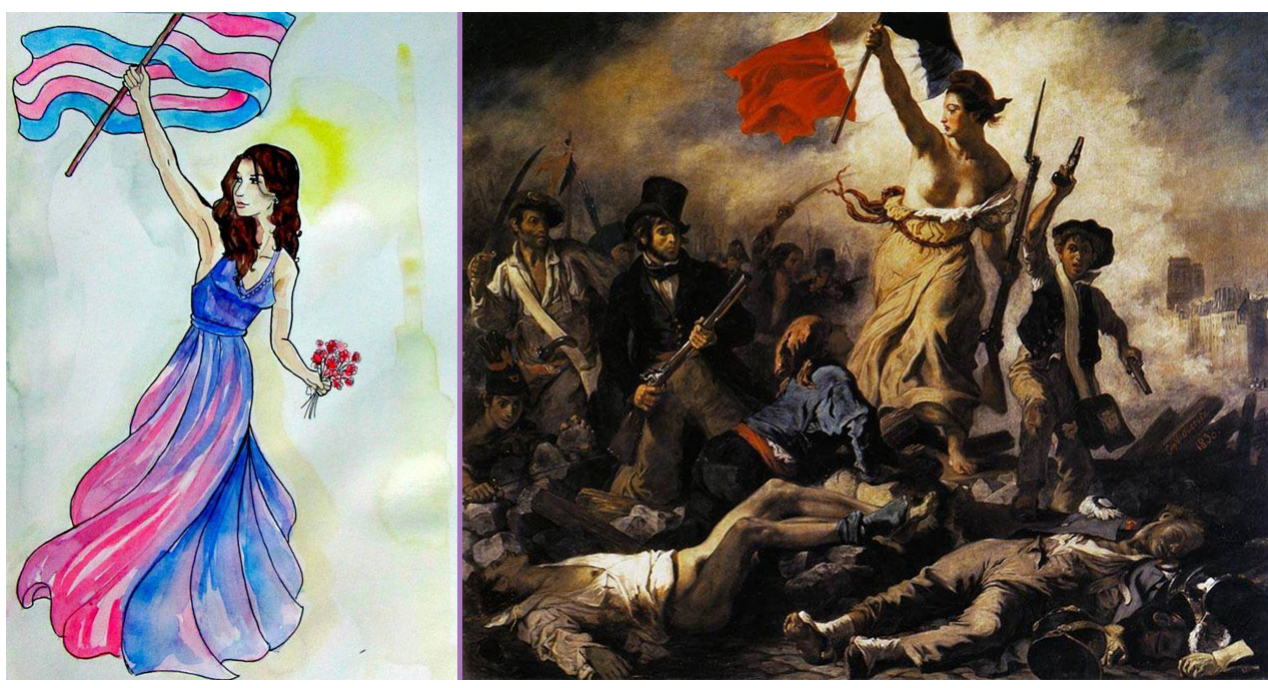

Fonte: página Travesti Reflexiva / reprodução de internet.

Se a pintura francesa é um dos principais símbolos da Revolução de Julho de 1830, que derrubou o governo de Carlos X, a ilustração da Travesti Reflexiva representa a oposição aos regimes impostos pelo pensamento normativo, defensor de que os indivíduos devem aprender a conviver com a identidade que lhe foi dada pela sociedade, medicina, igreja, etc.

Ao invés da brutalidade da arma de fogo, segurada na mão esquerda da pintura francesa, um delicado ramalhete é sustentado pela ilustração da página, como se esta fosse uma nova forma de lutar pelos direitos desse povo, uma guerra de ideias e discursos, que prefere a beleza e suavidade das flores à solidez e brutalidade da bala.

Outra imagem que chama atenção na página é a utilizada na capa (Fig. 3). Agora, ao invés de 
erguer a bandeira, a ilustração da Travesti Reflexiva está usando-a estampada em um vestido. A bandeira faz parte do corpo daquela representação, toca sua pele, lhe cobre e veste de seu próprio orgulho, que zomba da cara daqueles que acreditam na necessidade de uma legitimação do Estado e das tantas outras formas de controle.

Fig. 3: Vestida de orgulho, Sofia ironiza o pensamento TERF

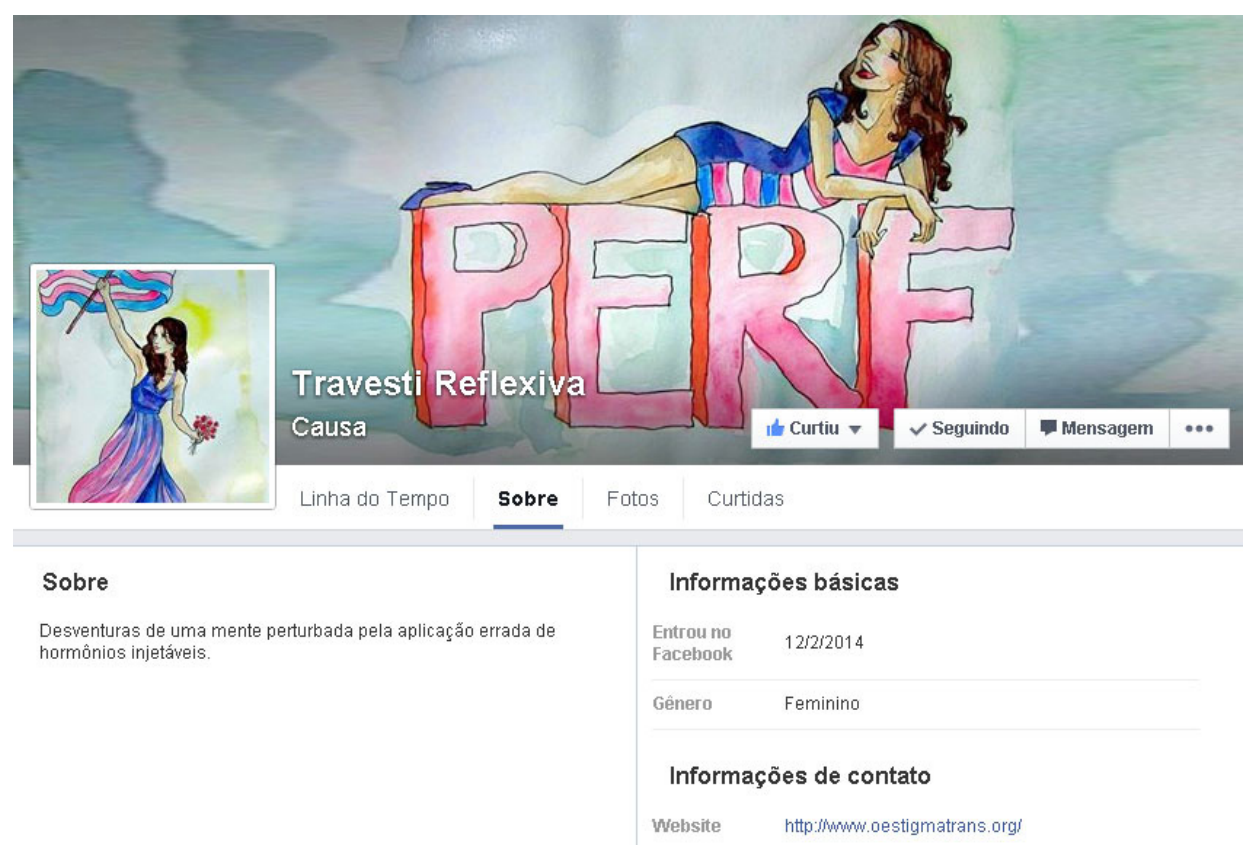

Fonte: página Travesti Reflexiva.

A figura, antes em pé de braço levantado e olhar compenetrante, agora está deitada sobre a palavra "PERF" (abreviação para perfeitinha, como descreve a dona da página), uma ironia em alusão ao acrônimo TERF (Trans Exclusionary Radical Feminists), sigla usada para designar as feministas radicais que não reconhecem as mulheres trans como pertencentes ao universo feminino. Na imagem, a representação de Sofia Favero tem ar debochado, ri e não se importa com a opinião daquelas a quem ironiza.

\section{Imagens e imaginários queer: criando reflexões através das postagens}

Muitos teóricos de estudos queer afirmam que as escolas não têm conseguido obter êxito quando se pensa no que deveria ser um discurso educativo acerca das múltiplas possibilidades de gênero, seja porque as instituições de ensino estão baseadas em fundamentos heteronormativos ou porque, mesmo quando apresentam sexualidades "desviantes", como a homossexual, continuam pregando modelos binários de sexualidade, não preparado os jovens para as múltiplas realidades de gênero.

Em Teoria Queer: um aprendizado pelas diferenças, Richard Miskolci reforça esse pensamento, afirmando que investir em modelos que pensam a sexualidade e as identidades de gênero a partir de fatores limitados é no mínimo equivocado, uma vez que não muda em grande escala os paradigmas que circulam a sociedade. 
A esfera da educação não precisa, e, na minha opinião, nem deve, seguir essa lógica que busca trocar a formação heterossexista existente por outra simplesmente binária, como a que opõe homem e mulher, masculino e feminino, hétero e homo. $\mathrm{Ou}$, ainda, por outra circunstância aos termos de uma sigla (LGBT), um número limitado de formas de identificação. Em outras palavras, pouco adianta apenas trocar os sinais: se antes se educava todo mundo para a heterossexualidade, punindo ou ignorando quem não a seguisse, passar a educar para o binário, para ser hétero ou homo (...) apenas ampliando o número de identidades disponíveis no presente (MISKOLCI, 2012, p.18)

Baseado no pensamento do autor, podemos afirmar que a página Travesti Reflexiva, dentro dos limites existentes para se afirmar uma pedagogia pelas redes sociais, pode ser considerado um importante espaço potencial para se pensar novas possibilidades sobre sexualidade e gênero. Uma imagem (Fig. 4) publicada no dia 5 de junho de 2014 exemplifica a afirmação.

Fig. 4: complexidade aos modelos simplificados
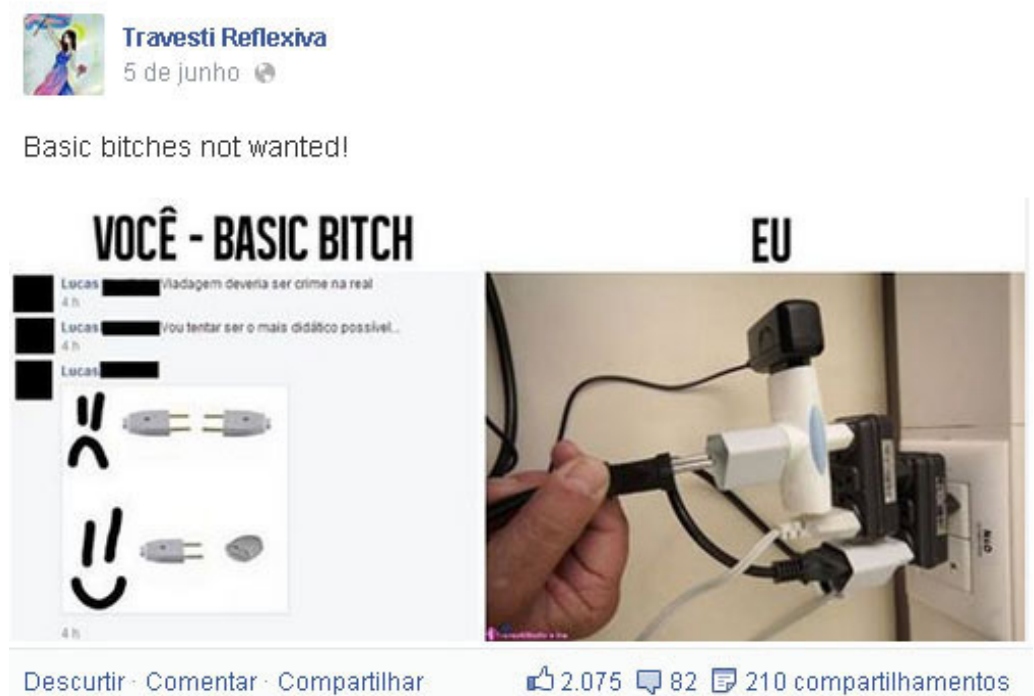

Fonte: página Travesti Reflexiva.

Uma pessoa identificada como "Lucas" deixa um recado dizendo que "Viadagem deveria ser crime", já que não é algo natural. Para exemplificar sua afirmação ele tenta "ser o mais didático possível". Para isso, ilustra com duas imagens de plugues de tomadas.

A primeira, ao lado de um emoticon em desaprovação, mostra dois plugues de dois pinos que não têm como encaixar-se um no outro, fazendo referência a dois pênis; a segunda imagem, com um plugue de entrada e um de encaixe é apresentado ao lado de um emoticon feliz, uma vez que ali há possibilidade de encaixe, em referência ao pênis e vagina.

Para criticar o usuário sem perder o humor da página, a proprietária posta uma terceira imagem de uma única tomada recebendo diversos plugues, com cores, tamanhos e tipos distintos, reforçando a ideia de possibilidades múltiplas de sexualidade. A ideia é exemplificada em outras postagens, como a do dia 28 de junho de 2014 (Fig. 5). A foto faz referência a três portas de banheiro, cada 
qual estampada com representações dos cromossomos sexuais.

Fig. 5: Entre XX e XY há mais unicórnios do que se imagina

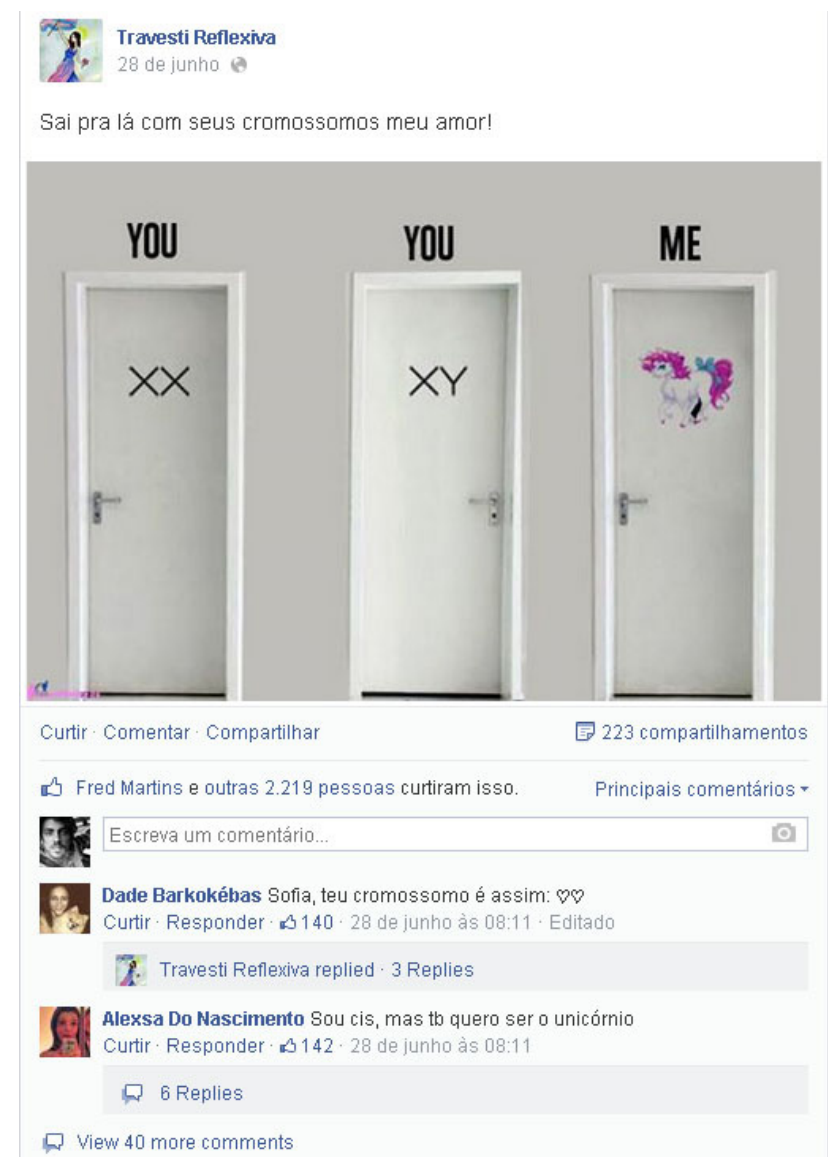

Fonte: página Travesti Reflexiva.

A primeira tem escrito XX (cromossomo feminino), a segunda XY (cromossomo masculino), enquanto a terceira possui um unicórnio, representando a multiplicidade, que nem todos podem ser definidos simplesmente por seus pares genéticos biológicos. Com 223 compartilhamentos, 2.213 curtidas (likes) e mais diversos comentários e subcomentários (replies, respostas direta aos comentários ou comentário do comentário), a fotografia desencadeia uma série de comentários que desdobram aquele pensamento inicial. Um exemplo disso é visto no comentário da usuária "Dade Barkokébas", que escreve "Sofia, teu cromossomo é assim $\checkmark \vee "$, reinventando simbolicamente a ordem cromossômica do sexo.

Além das imagens e vídeos, que representam direta e indiretamente a construção e afirmação das identidades que fogem às normas, há um forte empenho em trazer definições e reflexões concretas e pouco conhecidas ou debatidas na sociedade. Grande parte delas realizadas da forma simples, por textos longos e bem explicativos.

Na extensa publicação do dia 7 de julho de 2014 (Fig. 6), Sofia Favero tenta mostrar aos seguidores como surge e se constitui uma pessoa trans*, mas, ao fazer isso, coloca em questão não somente a formação da mulher trans, mas também como surgem as identidades socialmente impostas e 
como se opera a lógica hierárquica social. São trazidas à luz reflexões acerca da subordinação que a mulher cis tem na sociedade, ocupando cargos no mercado de trabalho inferiores aos dos homens cis, graças à falta de estímulo e castração do corpo imposta às mulheres.

Fig.6: Entre tantas possibilidades, por que resumir o mundo em identidades limitadas?

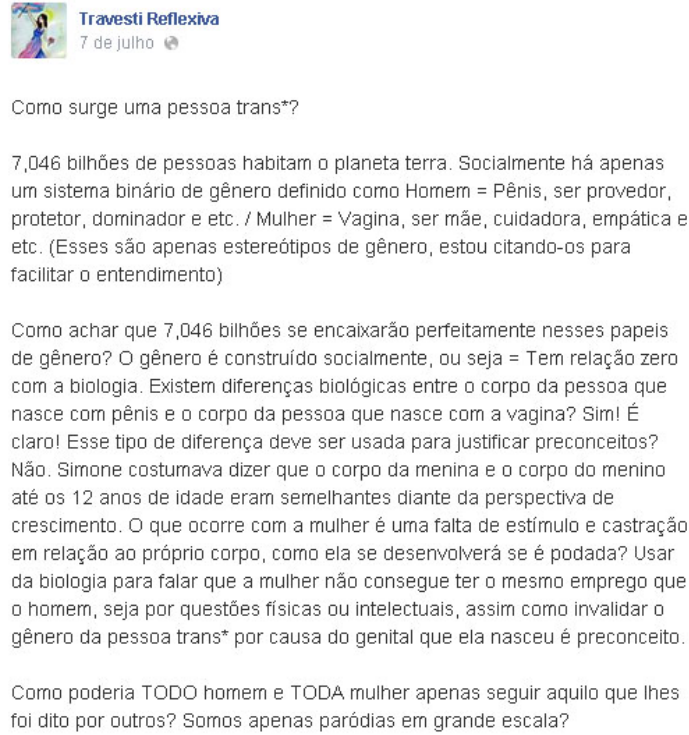

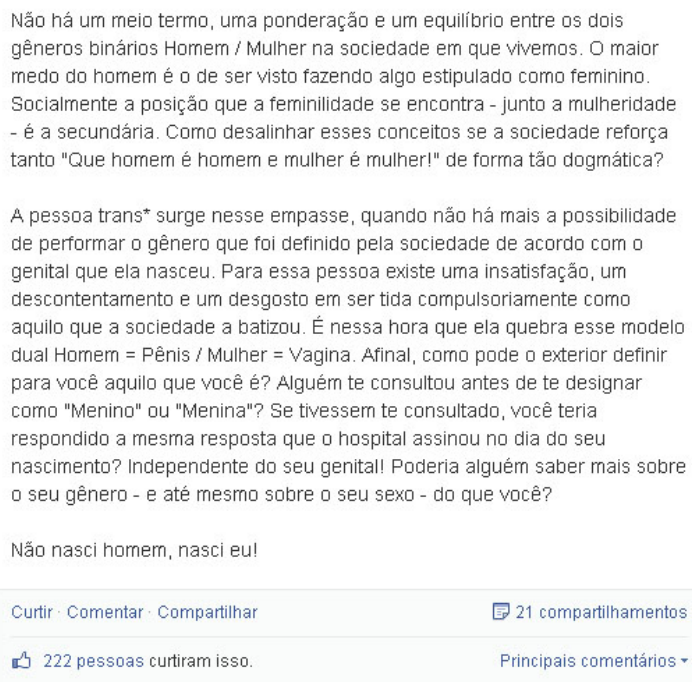

Fonte: página Travesti Reflexiva.

Para explicar o particular, no caso, a afirmação de um feminino transexual e, consequentemente, questionar a negação do mesmo imposta por diversos setores da sociedade, a página Travesti Reflexiva mostra que esse tipo de discussão engloba fatias maiores de pensamento, que devem colocar em declínio o discurso cartesiano de que o sexo biológico é fator preponderante para a determinação de uma identidade de gênero, considerada por muitos hermética e imutável.

Em Um corpo estranho: ensaios sobre sexualidade e teoria queer (2013), Guacira Lopes Louro coloca em tensão a identidade sólida e bem definida criada pelo pensamento normativo. Ao falar sobre essas imposições, ela diz que:

A identidade é assegurada através de conceitos estáveis de sexo-gênero e sexualidade; mas há sujeitos de gênero "incoerentes", "descontínuos", indivíduos que deixam de se conformar às normas generificadas de inteligibilidade cultural pelas quais todos deveriam ser definidos (LOURO, 2013, p.70)

Outro que também ressalta a importância de combater as ideias pré-estabelecidas acerca das identidades de gênero é Leandro Colling (2012), que, seguindo o mesmo pensamento publicado na postagem da página Travesti Reflexiva, questiona o pensamento raso ao compactar os indivíduos em apenas homens e mulheres biológicos, naturais.

Sexo/biologia/natureza, entendido aqui como a materialidade dos corpos, não determina o gênero da pessoa. Várias pessoas nascem com determinadas características corporais e não se identificam com o gênero que a sociedade exige para aquele corpo. Ou seja, não existe nenhuma garantia de que alguém com sexo 
masculino ou feminino será do gênero que a maioria entende como compatível com aquele sexo. O que existe é uma norma hegemônica que obriga, a todo custo e através de muita violência, que exista uma coerência entre a materialidade do corpo e o gênero (COLLING, 2012, p. 116)

$\mathrm{Na}$ conclusão da publicação acima mostrada, a proprietária da página afirma que "A pessoa trans* surge nesse impasse, quando não há mais a possibilidade de performar o gênero que foi definido pela sociedade de acordo com o genital que ela nasceu". Aquilo encarado como natural pela sociedade é algo que não pertence ao que deseja a/o trans*, logo a naturalidade socialmente imposta é simulacro para os indivíduos que transcendem tais regras.

\section{5. \#VaiTerQueerSim: o discurso que abala as normas}

São muitas as postagens explicativas na Travesti Reflexiva e rendem reflexões que extrapolam aquele espaço, uma vez que, ao serem compartilhadas, as mensagens permeiam diversas outras contas de usuários secundários e, por sua vez, usuários terceiros que sequer estão conectados àquela página, fato que por si já mostra a força da propagação de ideias que há nas redes sociais.

Entretanto, além dessas postagens diretas e explicativas acerca de um determinado tema (como na reflexão sobre como surge uma pessoa trans*), há várias postagens que ironizam as normas sociais e colocam em xeque os pensamentos conservadores. Muitas dessas publicações surgem em resposta direta a outras páginas que pregam e defendem os discursos normativos.

Exemplo pode ser visto nas publicações que ocorreram entre os dias 16 e 18 de julho de 2014 (Fig. 7), em resposta a uma postagem da página Parada Hetero Brasil, que se apresenta como uma resistência que tenta "Preservar a família tradicional, as liberdades individuais e o jeito normal de ser"11 (grifo meu). Na ocasião, a página publicou uma ilustração com um selo que dizia "Heterossexual. Isso é normal. 100\%", postagem esta que foi compartilhada por Sofia Favero na página Travesti Reflexiva.

11 Disponível em: http://on.fb.me/YqTpSO. Acessado em: 10/07/14. 
Fig. 7: Contra o selo heteronormativo (esq. sup.), carimbos queers!

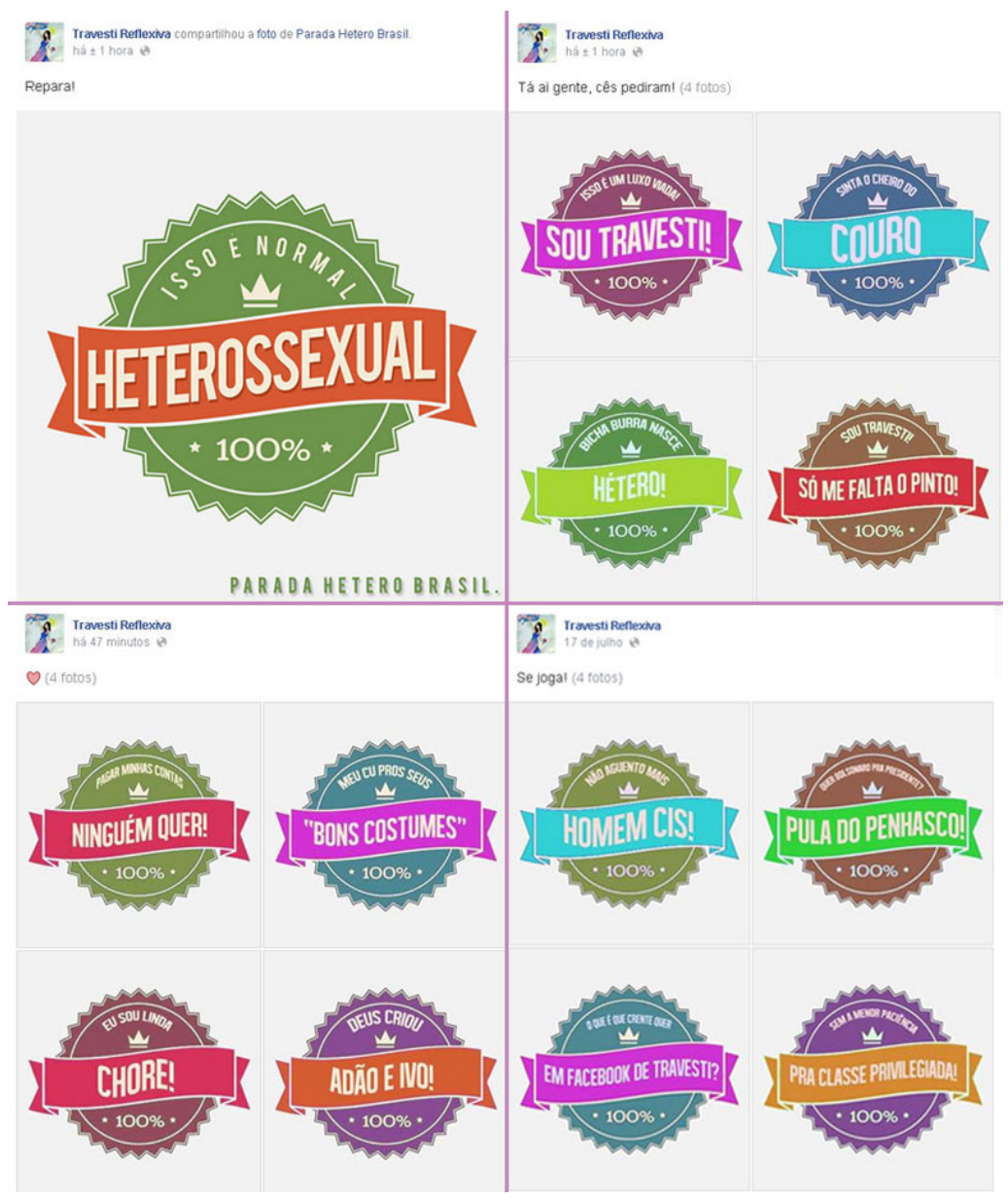

Fonte: página Travesti Reflexiva.

Ao invés de simplesmente denunciar o conteúdo, recurso do Facebook para aqueles que estão insatisfeitos com determinada postagem, a página Travesti Reflexiva copiou a arte usada pela Parada Hetero Brasil e criou uma série de outros selos com discursos contrários às normas impostas, como por exemplo: "Sou travesti! Isso é um luxo, viada! 100\%”, "Bicha burra nasce Hétero! 100\%", "Meu cu pros seus bons costumes. 100\%", "Sem menor paciência pra classe privilegiada. 100\%", "O que é que crente quer em Facebook de travesti? 100\%”, entre outros.

O uso da cópia para criticar aquilo afirmado como "100\% normal", aliando, a isto, diversos discursos antinormativos, mais uma vez quebra a intenção de mostrar a identidade de gênero ligada a uma natureza biológica, divina, ao ser humano como uma entidade fechada, centrada, sólida e não permeada pelos diversos processos identitários que a cultura apresenta. Se somos todos recortes daquilo que nos afeta e isso nos constrói enquanto indivíduos, não é um simples genital que nos define enquanto humanos "naturais". O natural é posto novamente em questionamento.

Em alusão as hashtags criadas antes e durante a Copa do Mundo 2014, quando usuários utilizaram \#NãoVaiTerCopa e \#VaiTerCopa em diversas redes sociais, a página Travesti Reflexiva passou a lançar postagens utilizando a mesma ideia discursiva, mas com alterações na escrita que deixaram mostravam o manifesto subversivo daquela comunidade, como nas postagens ocorridas entre os 
dias 7 e 16 de julho de 2014 (Fig. 8)

Fig. 8 - Beijos gay abalam a solidez quadrada das normas

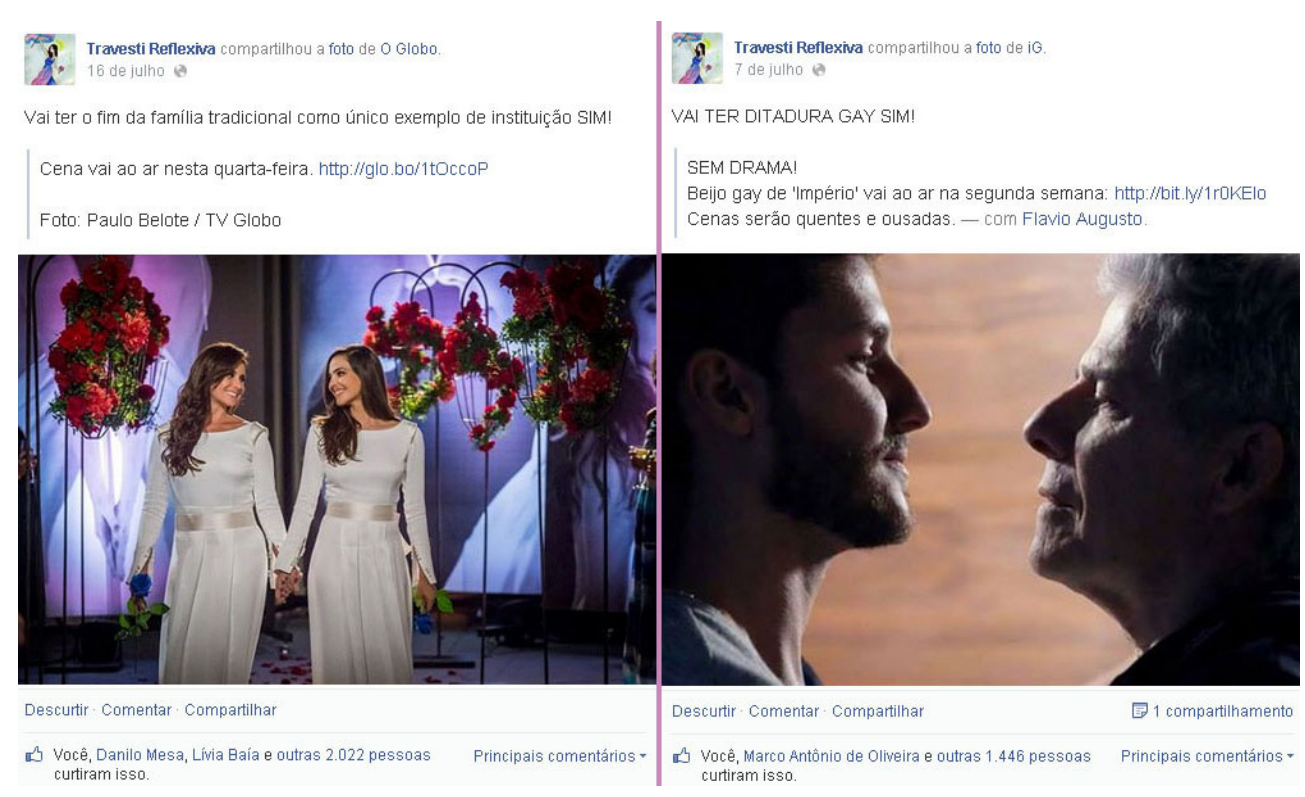

Fonte: página Travesti Reflexiva.

As postagens mostram duas notícias referentes às novelas com relações "não-tradicionais" exibidas em 2014, mais uma tentativa de abalar as estruturas do discurso cartesiano que impera a lógica binária de sexualidade e gênero, que por muito tempo influenciou a grande mídia brasileira a não exibir esse tipo de demonstração de afeto, considerada ofensiva por uma parcela da sociedade.

Para provocar esses discursos, as publicações aparecem com dizeres que incitam o caos alarmado pelo conservadorismo, afirmando que "Vai ter o fim da família tradicional como único exemplo de instituição SIM!" e "VAI TER DITADURA GAY SIM!", mostrando à sociedade que os sujeitos “desviantes" existem, estão sendo midiaticamente representados e não há como fugir dessas realidades.

$\mathrm{Na}$ análise se percebeu ainda que a página funciona também como uma cartografia daquilo que está sendo publicado acerca do universo trans* nas mídias jornalísticas do país (Fig. 9), sejam violências praticadas por criminosos, que elevam diariamente a taxa de homicídio das transexuais brasileiras, ou a violência cometida pela própria imprensa, que muitas vezes coisifica e espetaculariza a pessoa trans*. 
Fig. 9 - Múltiplas violências à pessoa trans*.

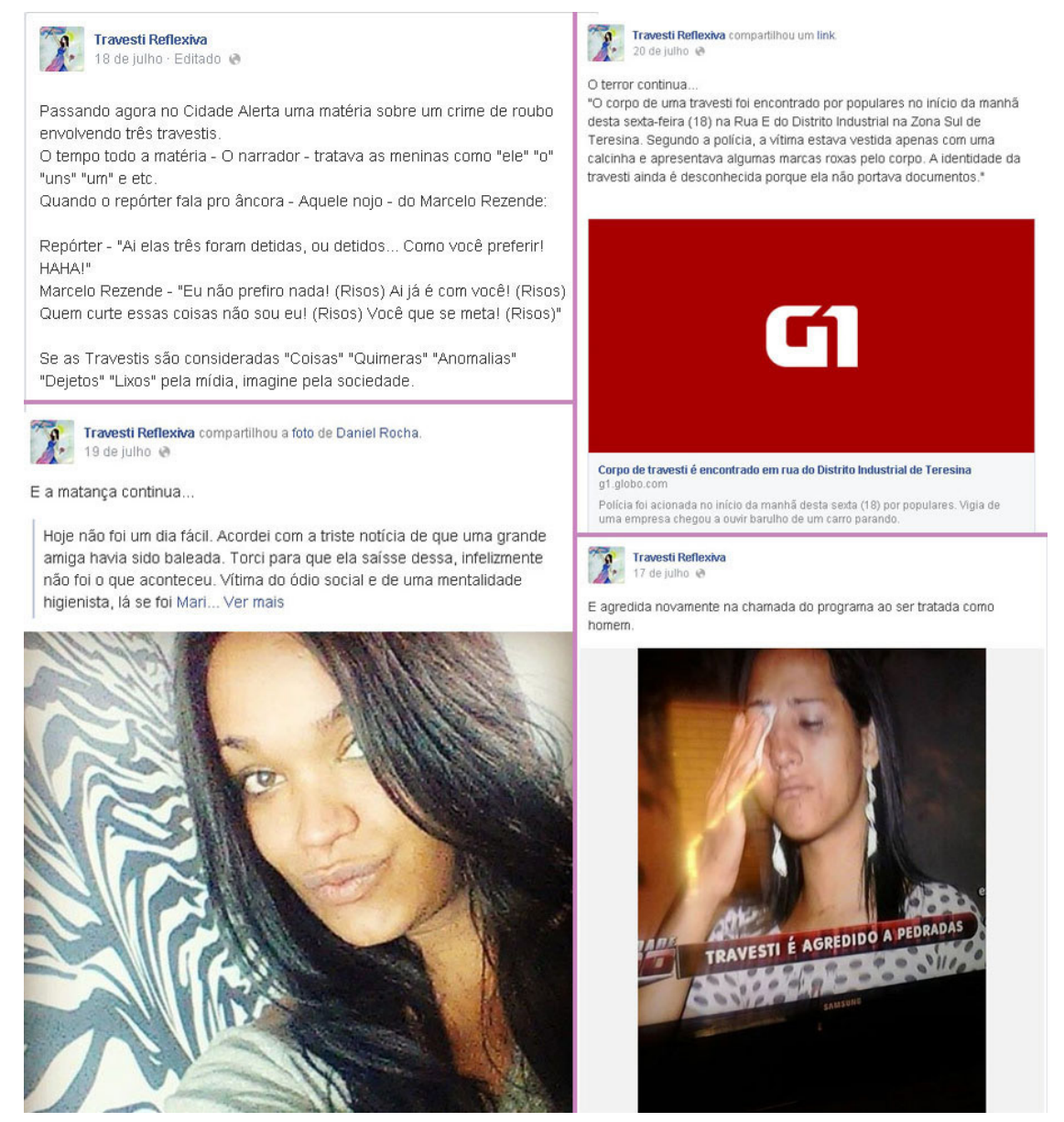

Fonte: página Travesti Reflexiva

A violência velada praticada pela mídia, ao desmerecer as transexuais, seja transformando uma notícia trágica em cômica ou simplesmente insistindo em se referir às mulheres trans pelo pronome masculino só contribuem para perpetuar os estigmas que tanto assolam os indivíduos que fogem às regras identitárias e sexuais impostas pela sociedade.

Esse registro é mostrado nas publicações acima. A primeira, do dia 17 de julho de 2014, mostra uma matéria televisiva sobre uma travesti agredida a pedradas. Além da violência sofrida, conforme evidencia a postagem, é realizada uma segunda agressão, quando, ao narrar a história, a imprensa se refere à vítima como homem.

Outro erro é apresentado na publicação do dia seguinte (18 de julho), quando Sofia Favero faz uma análise sobre a matéria policial do programa Cidade Alerta (TV Record) sobre um roubo envolvendo três travestis, as quais o repórter trata como "ele", "o", "um" e "uns". Ainda é apresentada uma transcrição do momento em que repórter e apresentador conversam sobre o caso:

\section{REPÓRTER:}

Aí elas três foram detidas... ou detidos... Como você preferir! (risos) 


\section{APRESENTADOR:}

Eu não prefiro nada! (risos). Aí já é com você (risos). Quem curte essas coisas não sou eu (risos). Você que se meta!

A falta de ética apresentada por uma categoria que, em tese, deveria tentar construir uma realidade melhor para os indivíduos, serve de termômetro para pensar como a sociedade trata e reconhece os indivíduos trans". Na conclusão de sua postagem, Sofia Favero reforça a afirmação. "Se as travestis são consideradas 'coisas', 'quimeras', 'anomalias', 'dejetos', 'lixos' pela mídia, imagine pela sociedade”.

O marginal - aqui entendido como o sujeito que está fora do restrito quadrado de indivíduos privilegiados composto pelas classes dominantes, formada, na maioria, por brancos, homens heterossexuais, letrados e de classe elevada - é tratado pela grande mídia como desmerecedor de maiores considerações.

Nesta lógica não importa se a travesti é tratada como "homem", "coisa" ou qualquer classificação que a ridicularize, uma vez que parte da grande mídia não está interessada em tratar com respeito as causas minoritárias, fato que impulsiona a criação dos estigmas para essa parcela da população. Quem observa bem isso é Leandro Colling (2012) ao falar que:

Quando uma pessoa é assassinada ou é vítima de algum outro tipo de violência e é branca, classe média alta, heterossexual, em geral, a imprensa noticia e acompanha o caso, com direito a sucessivas manchetes ou chamadas de primeira página. As dezenas de mortes que são registradas nos subúrbios das grandes cidades a cada final de semana quase sempre merecem apenas uma nota ou pequena notícia no interior dos jornais impressos. Quando um ou mais gays de classe média alta são espancados na Avenida Paulista, toda a imprensa cobre o assunto e se mostra sensibilizada com o aumento da violência. Quando travestis são assassinadas brutalmente não vemos a mesma sensibilização e espaço na mídia. Ou seja, algumas pessoas não podem ser violentadas e outras, abjetas, podem. Por isso, é necessária a politização do abjeto, o que passa pela humanização de todas as pessoas, no sentido de revelar que temos histórias de vidas complexas, sofremos e merecemos ser felizes (COLLING, 2012, p. 126).

É nítido o papel social que existe na página Travesti Reflexiva. Além de mostrar os equívocos cometidos pela grande mídia, assim como comete parte da sociedade, que tende a espelhar determinadas "verdades" construídas pela imprensa, a dona da página tenta destruir os vícios de linguagem e a antiética jornalística existente na atualidade. Assim foi criada uma cartilha destinada à imprensa ${ }^{12}$, para que possíveis erros e desrespeitos deixem de fazer parte das pautas midiáticas. $\mathrm{Na}$ descrição do material, a dona da página diz que

Muitos jornalistas passam por uma enorme dificuldade na hora de redigir matérias que tratam de assuntos relacionados a Transexualidade, Travestilidade ou Transgeneridade. Sabendo disso, resolvi criar um guia prático e de fácil entendimento para que os próprios jornalistas se policiem e não comentam mais gafes desrespeitosas para com as pessoas Transexuais, Travestis e Transgêneras (FAVERO, 2014)

12 Disponível em http://www.oestigmatrans.org/guia-basico-para-jornalistas/. Acessado em: 11/07/14. 
O papel do jornalista, que seria de apresentar de forma ética e desprendida de preconceitos a realidade daquelas pessoas retratadas nas matérias, não é exercido nos casos apresentados. Mais que simplesmente criticar os ocorridos, é apresentada uma solução para que o problema não volte a ocorrer, mais uma forma de utilizar aquele espaço não somente como ambiente para discussões sobre as questões de gênero, mas também propor soluções para os possíveis transtornos.

\section{Considerações finais}

Para além das rasas discussões existentes nas redes sociais, nas quais os indivíduos mais estão preocupados com o show do eu e a espetacularização da vida íntima (SIBILIA, 2008), a página Travesti Reflexiva se tornou um espaço importante para trazer à luz questionamentos acerca das questões de gênero e pode ser considerada uma excelente ferramenta para a propagação de um pensamento queer acerca das identidades de gênero.

Não que a Teoria Queer seja um saber sólido, uma vez que tudo que se aproxima do estado bruto do pensamento tende a se distanciar do refletir queer. Mas naquele pequeno espaço virtual é possível encontrar fortes bandeiras da subversão defendida pelos autores dessa corrente. A não aceitação das normas socialmente impostas, o questionamento do que vem a ser encarado como "o correto" na sociedade e a liberdade ao corpo são só pequenas fagulhas defendidas pelos pensadores queer e são constantemente iluminadas pela página Travesti Reflexiva.

Se as formas de preconceito atingem transversalmente todas as minorias sociais oprimidas, a página tenta expandir o leque das causas defendidas. Naquele espaço as concepções pré-estabelecidas são colocadas em tensão, abordando assuntos dos mais variados possíveis, como reconhecimento das mulheres transgênero, a defesa do direito LGBT, a independência da mulher cisgênero, o combate ao patriarcado e à heteronormatividade, a quebra do modelo binário de gênero, entre vários outros temas que fogem ao estabelecido como "certo".

São ampliadas as capacidades de pertencimento dos indivíduos, apresentadas novas formas de pensar a constituição de um “eu”, que não é natural, ao contrário do que o discurso conservador tenta definir, e sim um sujeito construído com base em sua trajetória de apropriações imagéticas da vida.

Apesar de pertencer a uma pessoa, no caso à proprietária Sofia Favero, aquele espaço tem como ambiência os vários indivíduos que compõem o mundo, seja ele homem, mulher ou simplesmente um sujeito em trânsito, que não se define e nem se preocupa em estar enquadrado em qualquer uma dessas rotulações, ou seja, são pessoas simplesmente inconclusas (LOURO, 2013).

Numa sociedade na qual ainda é forte a presença do discurso dominante, que tenta cristalizar as pluralidades dos indivíduos, amarrando suas potencialidades, espaços como a página Travesti Reflexiva servem para colorir aquilo que é posto em escalas de cinza; se ainda existem discursos opressivos e solidificantes, é a partir de ambientes como esses que será possível, pouco a pouco, dia a dia, derreter as formas retangulares de se pensar a vida. 


\section{Referências}

AQUINO, Camila; MARTELLI, Andrea C. Escola e educação sexual: uma relação necessária. IX Seminário ANPED SUL. Caxias do Sul, RS, 2012.

COLLING, Leandro. Como pode a mídia ajudar na luta pelo respeito à diversidade sexual e de gênero? In: PELÚCIO, L. (et al.). Marília: Oficina Universitária; São Paulo: Cultura Acadêmica, 2012, p. $109-128$.

FAVERO, Sofia. Página Travesti Reflexiva. Disponível em: https://www.facebook.com/ TReflexiva?fref=ts. Acessado em: 10/06/14.

JESUS, Jaqueline G. Orientações sobre identidade de gênero: conceitos e termos. Brasília: Autora, 2012.

LOURO, Guacira L. Um corpo estranho: ensaios sobre sexualidade e teoria queer. Belo Horizonte: Autêntica Editora, 2013.

MISKOLCI, Richard. Teoria Queer: um aprendizado pelas diferenças. Belo Horizonte: Autêntica Editora, 2012.

PAIVA, Cláudio C. Hermes no ciberespaço: uma interpretação da comunicação e cultura na era digital. João Pessoa: Editora da UFPB, 2013.

RECUERO, Raquel. Redes sociais na internet. Porto Alegre: Sulina, 2009.

SIBILIA, Paula. O show do eu: a intimidade como espetáculo. Rio de Janeiro: Nova Fronteira, 2008. 